\title{
Analysis and Comparison of Voltage Dependent Charging Strategies for Single-Phase Electric Vehicles in an Unbalanced Danish Distribution Grid
}

\author{
Álvarez, Jorge Nájera; Knezovic, Katarina; Marinelli, Mattia
}

Published in:

Proceedings of the 51st International Universities Power Engineering Conference

Link to article, DOI:

10.1109/UPEC.2016.8114062

Publication date:

2016

Document Version

Peer reviewed version

Link back to DTU Orbit

Citation (APA):

Álvarez, J. N., Knezovic, K., \& Marinelli, M. (2016). Analysis and Comparison of Voltage Dependent Charging Strategies for Single-Phase Electric Vehicles in an Unbalanced Danish Distribution Grid. In Proceedings of the 51st International Universities Power Engineering Conference IEEE.

https://doi.org/10.1109/UPEC.2016.8114062

\section{General rights}

Copyright and moral rights for the publications made accessible in the public portal are retained by the authors and/or other copyright owners and it is a condition of accessing publications that users recognise and abide by the legal requirements associated with these rights.

- Users may download and print one copy of any publication from the public portal for the purpose of private study or research.

- You may not further distribute the material or use it for any profit-making activity or commercial gain

- You may freely distribute the URL identifying the publication in the public portal 


\title{
Analysis and Comparison of Voltage Dependent Charging Strategies for Single-Phase Electric Vehicles in an Unbalanced Danish Distribution Grid
}

\author{
Jorge Nájera Álvarez, Katarina Knezović, Mattia Marinelli \\ Center for Electric Power and Energy, Department of Electrical Engineering, DTU - Technical University of Denmark \\ Contact person: Mattia Marinelli (matm@elektro.dtu.dk)
}

\begin{abstract}
This paper studies four voltage dependent solutions for modulating the charging of multiple Electric Vehicles (EVs) in a real Danish network. Uncontrolled EV charging, especially in grid with high EV penetration, can result in overloaded lines and transformers, low-voltages and other performance degradations which lead to poor quality of supply. Therefore, a decentralized control for modulating the EVs' charging current is developed, which sets the $\mathrm{EV}$ reference current based on the phase-to-neutral voltage at the EV connection node. Due to the controller's decentralised feature, EVs plugged-in on phases with lower voltages are constrained during the charging period. In order to solve instability issues which may occur due to lack of communication between the controllers, several improvements are applied to the aforementioned droop control. Simulation results demonstrate the performance of the voltage dependent controls for a real Danish distribution grid.
\end{abstract}

Keywords-Distribution network, Droop control, Electric vehicles, Voltage control

\section{INTRODUCTION}

Electric vehicles (EVs) are, slowly but doubtlessly, becoming a real alternative to traditional combustion engine cars. In countries like Denmark, where the EV integration policies are favourable and the investments for the EVs infrastructures are substantial, the number of EVs is expected to grow significantly in the following years [1]. Consequently, with high local EV penetrations, it is likely that distribution system operators will face scenarios where increased EV power demand together with the already present residential demand, can question the reliability and the security of the network [2]. Due to these situations, charging patterns of EVs connected to a distribution network have to be controlled in order to avoid the need for grid reinforcement.

When distribution lines are heavily loaded, the power increase caused by the batteries can over-stress those lines, which results in decreasing voltage gradients, especially in unbalanced networks. According to the standard EN 50160 the 10 minutes average rms voltage values have to be within the \pm $10 \%$ range of the nominal voltage for $95 \%$ of the weekly time in order to have a reliable performance of the power system [3].

Previous publications have assessed the voltage management provided by EVs in distribution networks by developing a voltage controller that takes into consideration the voltage at the point of charging, the EV battery State of Charge (SOC) and the preferred end-of-charge time for the EV owner [4]. In a similar way, other works appraise the lowvoltages concern with an EV charging controller based on a fuzzy logic-based charging algorithm, which request information about the EV battery SOC, the energy price and the voltage [5].

This paper develops a voltage dependent solution for a single-phase EV charging current in a real unbalanced Danish low voltage distribution network, taking into account that the phase-to-neutral voltage at each network node has to satisfy the aforementioned standard, i.e., it is only dependent on local voltage measurements.

As the model represents a real low voltage network with real consumption data, this work could be used by the distribution system operator (DSO) as a guideline to fulfil the voltage requirements in their low voltage network, and evaluate the impacts of using a controller like the one presented in this paper. Due to its simplicity, this local droop controller could be implemented in any distribution network with EV penetration, regardless on the location and the size of the system.

\section{MEthodology}

\section{A. Low-voltage grid}

The analysed network is a real Danish low-voltage grid located in eastern Denmark, which has been modelled in Matlab Simulink SimPowerSystems based on real measurement data. This subsection will describe the main features of the network represented in Fig. 1; further information can be found in [6]. The MV/LV $400 \mathrm{kVA}$ transformer connects the $10 \mathrm{kV}$ medium voltage network with four $0.42 \mathrm{kV}$ distribution feeders, and it has a three-phase short circuit power equal to $10 \mathrm{MVA}$. It has been assumed that the voltage at the transformer MV voltage side is kept at 1 p.u.. Considering the decreasing voltage gradients and the previously standard mentioned, this assumption establishes that the maximum allowed network voltage droop for the scenarios described in this paper is equal to 0.1 p.u., which does not have to be necessarily the case. In a scenario with a 
voltage at the transformer MV voltage side below the nominal value, the maximum acceptable voltage drop would be lower than 0.1 p.u. in order to satisfy the standard. Consequently, the charging power demanded by EVs would have to be more reduced.

The observed low-voltage network consists of 14 nodes, 13 line segments and 43 households classified in two groups according to their location and consumption characteristics. Households marked with green are equipped with an EV and a PV installation, and they are principally located in area B, i.e. Græsmarken Street. On the other hand, households located in area A, i.e. Hørmarken Street, are equipped with only electric vehicles. Area $\mathrm{C}$ represents three feeders connected to the same transformer, but for whom the individual household data is not available, so they have been represented as a single aggregated load. The consumption and PV production patterns are based on real metering data on hourly basis.

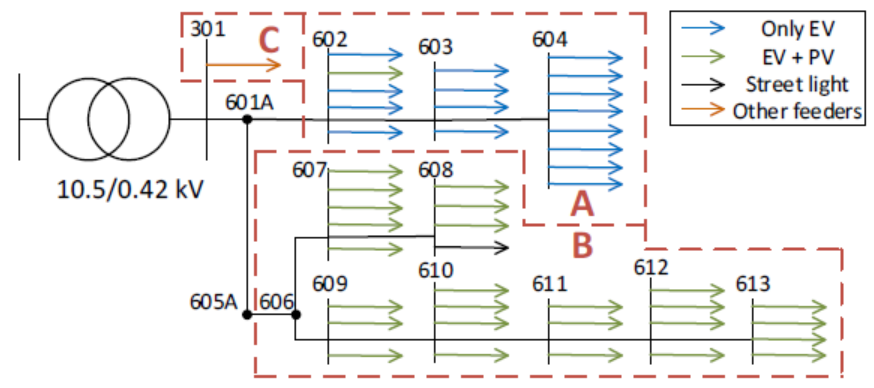

Fig. 1. Single phase diagram of Borup network [6].

\section{B. Electric vehicle battery model}

A lithium-ion (Li-ion) battery model has been developed in Matlab Simulink SimpowerSystems in order to characterize the plugged-in EVs in the low voltage grid. This storage model, schematized in Fig. 2, is based on the models described and validated in [7], [8]. The model's state variables are the State of Charge (SOC) and the Voltage, whereas the rest of the variables such as Open Circuit Voltage (OCV), internal resistance, protection and limitation boundaries are dependent on those state variables. Moreover, there is no thermal dynamic block due to the lack of information about it. Besides, the maximum EV charging power for the scenarios studied in this paper is equal to $3.7 \mathrm{~kW}$, which corresponds to the $22.7 \%$ of the nominal battery power $(16.3 \mathrm{~kW})$, so it can be assumed that the temperature is not going to be significantly affected by the slow charging process and the thermal dynamics can be disregarded for this analysis. The chosen battery parameters represent the battery inside a Peugeot Ion and can be seen in TABLE I [9].

The model's input is the reference current, i.e. the current that the EV user wants to store or to take out from the battery. In order to find the battery reference power, the input current is multiplied by the voltage and then by the inverter's efficiency, which is equal to $73.2 \%$. The efficiency values are based on experiments performed on Peugeot Ion in SYSLAB PowerLabDK [10].
TABLE I

LI-ION CELL AND BATTERY NOMINAL PARAMETERS

\begin{tabular}{|c|c|}
\hline Parameters & Values \\
\hline Cell voltage (V) & 3.7 \\
\hline Cell current (A) & 50 \\
\hline Cell max/min voltage (V) & $2.75 / 4.10$ \\
\hline Battery power $(\mathrm{kW})$ & 16.3 \\
\hline Battery Energy $(\mathrm{kWh})$ & 16.3 \\
\hline
\end{tabular}

The reference power, together with the battery voltage and the SOC, is used to calculate a battery reference current that forces the battery flowing current to keep its value below the maximum current that can be sent through the cell. It also limits the current absorption when the SOC is at its maximum, as well as the current delivery when the SOC is at its minimum. The SOC is previously calculated knowing the initial SOC, the battery flowing current and the battery total capacity. Afterwards, the difference between the battery reference current and the battery flowing current is moved forward into a proportional-integral (PI) controller. This controller calculates the battery reference voltage. At last, the battery reference voltage together with the SOC allows the model to calculate the rest of the variables like OCV, battery flowing current, battery voltage and battery flowing power.

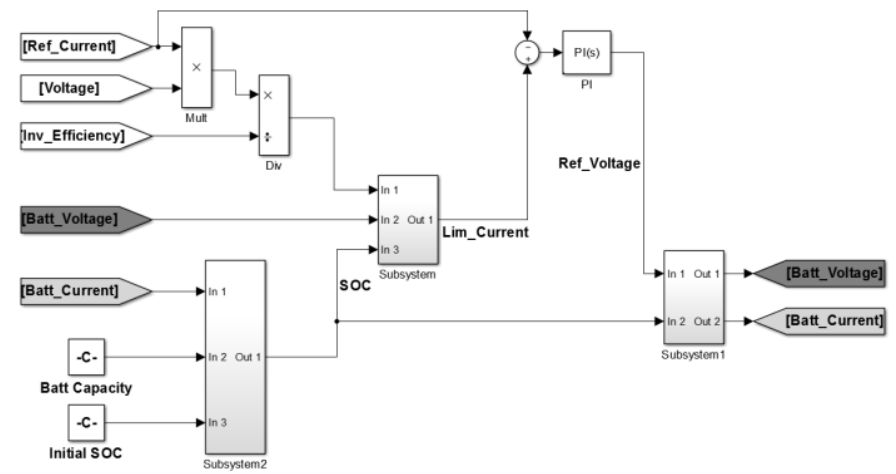

Fig. 2. Schematic of the EV battery model.

\section{Controllers description}

In order to satisfy the foregoing voltage standard, four decentralized control variations for modulating the EVs' charging current have been developed. Controllers are essentially a simple droop control, which has been installed in every Electric Vehicle Supply Equipment (EVSE). Due to their simplicity, the controllers are easy to implement with already available equipment, e.g. by using the Phoenix controller in the EV charging station [11], [12]. Furthermore, such controllers are only dependent on local phase-to-neutral voltage measurements which are already available inside the EVSE; hence, they are relatively cheap compared to the other centralized or more complex controllers which require costly communication infrastructure.

Voltages in an unbalanced network have different values on different phases, reaching lower values on the most loaded phases and on the nodes furthest from the transformer. In the same way, a droop control which reacts solely on the EV connection point voltage will have different behaviour 
depending on the phase and the node to which the EV is connected. Consequently, EVs connected to more loaded phases will be "penalized" with a reduced reference current due to the low voltage on the connected phase. This would, as expected, influence the charging time and the EV efficiency resulting in more consumed energy and accordingly higher energy cost for the customer. The developed charging controllers are explained further on.

\section{C.1. Controller 1 (C1):}

The first developed controller calculates the reference battery current according to the droop characteristic presented in Fig. 3. This table establishes the maximum reference current, i.e. $16 \mathrm{~A}$, when the measured voltage is above 0.95 p.u. For voltages below 0.95 p.u. the reference current gradually decreases, reaching its minimum value of $6 \mathrm{~A}$ when the measured voltage is equal to 0.9 p.u., as this is the minimum acceptable voltage for the distribution network. EVs are not allowed to charge their batteries if the voltage is below 0.9 p.u. so the current is set to zero below this point.

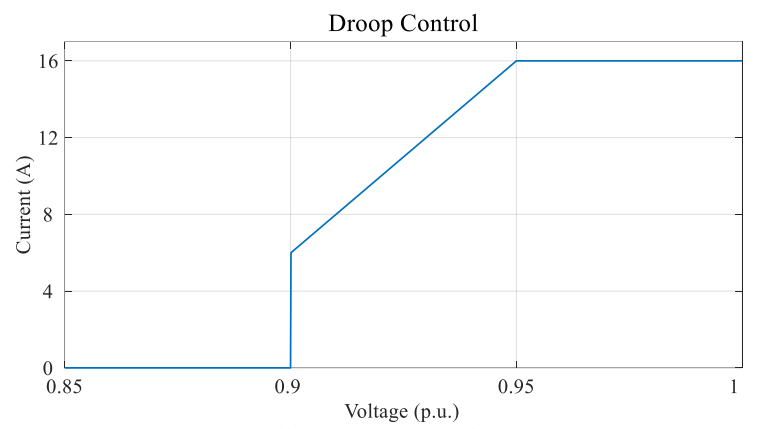

Fig. 3. Droop Control Controller 1 characteristic.

\section{C.2. Controller 2 (C2):}

The second controller sets the minimum charging current to 6A until the EVs are fully charged, as it can be seen on Fig. 4. For voltages above 0.9 p.u. this controller has the same behaviour as the controller $\mathrm{C} 1$. This controller is going to be the first one to be implemented on the test grid.

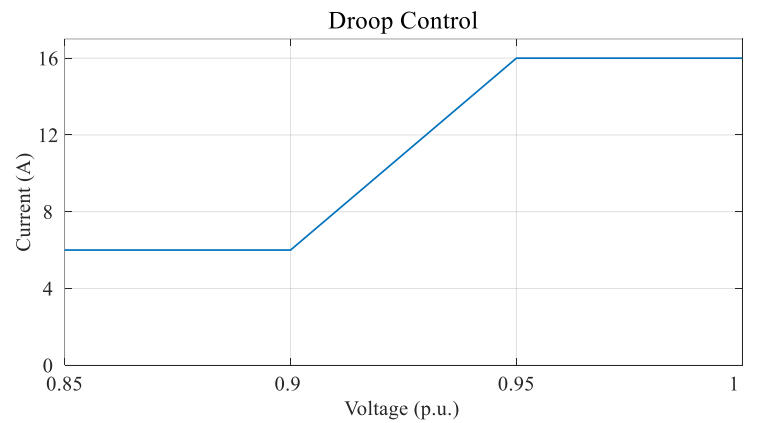

Fig. 4. Droop Control Controller 2 characteristic.

\section{C.3. Controller 3 (C3):}

The third controller implements the droop characteristic presented in Fig. 3, with the difference that the input to that characteristic is the average voltage measured every 30 seconds, i.e., this controller checks the voltage and sets the current every 30 seconds instead of doing it every second, as it is in controllers $\mathrm{C} 1$ and $\mathrm{C} 2$. This controller is also equipped with a random delay for every $\mathrm{EV}$ in order to uncouple the EVs charge, i.e., the controller tries to unsynchronise all EVs so the network has some seconds to stabilize after a few EVs have changed their charging current.

\section{C.4. Controller 4 (C4)}

The fourth controller implements the same droop characteristic as controllers $\mathrm{C} 1$ and $\mathrm{C} 3$ (Fig. 3), but with the addition of a hysteresis comparator block. This controller works in a similar way as a Schmitt trigger [13]. Fig. 5 illustrates this behaviour. If voltage decreases from values above 0.9 p.u. to values below 0.9 p.u., the droop control follows the blue line, and if voltage grows from values below 0.9 p.u., it follows the red line. The red line grows from zero to $10 \mathrm{~A}$ when the voltage is equal to 0.92 p.u. This voltage value has been tuned for this specific test case, and can be set to a different value for other applications or scenarios.

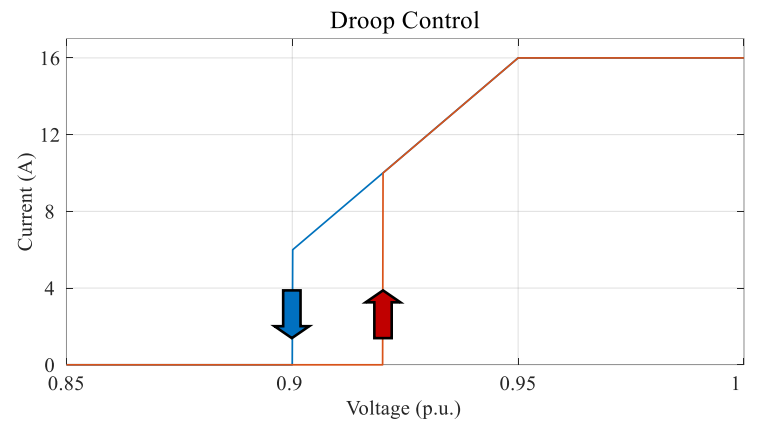

Fig. 5. Droop Control Controller 4 characteristic.

\section{Simulation environment and conducted scenarios}

Five scenarios have been considered for the analysis in this paper: Scenario 0, where the decentralized voltage control is not implemented and $\mathrm{EV}$ batteries can charge without restriction, and Scenarios $\mathrm{C} 1$ to $\mathrm{C} 4$ where the $\mathrm{EV}$ battery reference current is set by the controllers previously described. Simulations of the different scenarios have been carried out in Matlab Simulink SimpowerSystems.

Simulations are conducted for a 24 hour period, from 12:00 (noon) one day to 12:00 (noon) the following day, with a variable step time of maximum 1 minute and minimum 0.001 seconds. The selected day is a typical winter day, when the power demanded by the households is high due to the heating need while the PV production is at its lowest. The winter day can be seen as the worst case scenario since the line loading is higher than in any other season. Due to this already high loading, power demanded by the EVs will have a considerable influence on the grid as it is decreasing the already low voltage values. The initial SOC is assumed to be 0.2 for all EVs, and they are all plugged-in at the same time, at 19:00 h, to represent the typical dumb charging behaviour seen as the worst case for the DSO.

Loading is not equally distributed between the three phases. The grid is heavily unbalanced and, based on measurements at the transformer level, phase loading is divided as follows: 
$42 \%$ for phase $a$, and $29 \%$ for phases $b$ and $c$. Voltage levels at the most important nodes on the most loaded phase (phase a) when EVs are not connected are represented in Fig. 6.

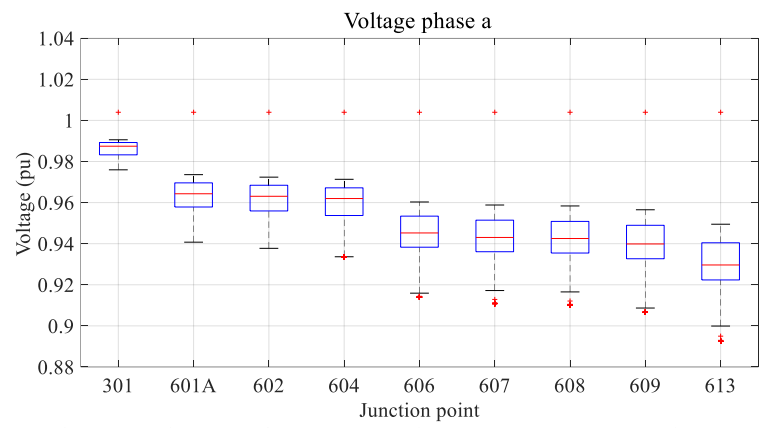

Fig. 6. Phase $a$ voltages at important nodes - EVs not connected.

The blue box indicates $50 \%$ of simulation results within the covered range where the red line is the median value. Upper and lower quartiles, i.e. $25 \%$ of the data are located within the black lines called "whiskers". Extreme cases are marked with red plus signs. As it can be seen, there are voltages below 0.9 p.u. at node 613 (the node located furthest from the transformer) even when no EVs are connected. Fig. 7 shows the time-voltage curve for the same case, which confirms that at 20:00 the phase $a$ voltage reaches a value around $0.89 \mathrm{p} . \mathrm{u}$ on phase $a$.

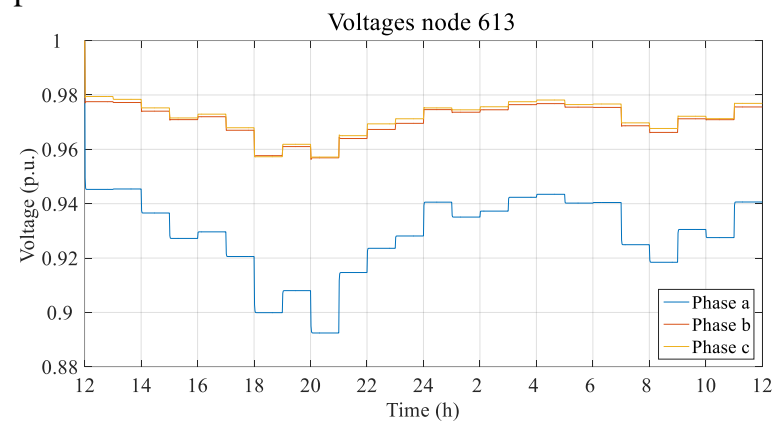

Fig. 7. Phase voltages at node 613 - EVs not connected.

\section{RESULTS AND DISCUSSIONS}

Voltage levels at the most important nodes and time-voltage curve at node 613 for Scenario 0 are illustrated in Fig. 8 and Fig. 9. Voltage values are, as expected, really low during the charging hours. It can be clearly seen in Fig. 9 that EVs stop charging around 01:00 $\mathrm{h}$, when their batteries are fully charged, i.e. SOC equal to $100 \%$. From that moment on, phase voltages follow the same behaviour as voltages represented in Fig. 7, since EVs are not demanding more power.

Voltage values reached during the EVs' charge in Scenario 0 are not compliant with the standards, so a charging control strategy is required in order to improve the reliability of the network. Time-voltage curve at node 613 for the rest of Scenarios are represented in Fig. 11, Fig. 12, Fig. 13 and Fig. 14.

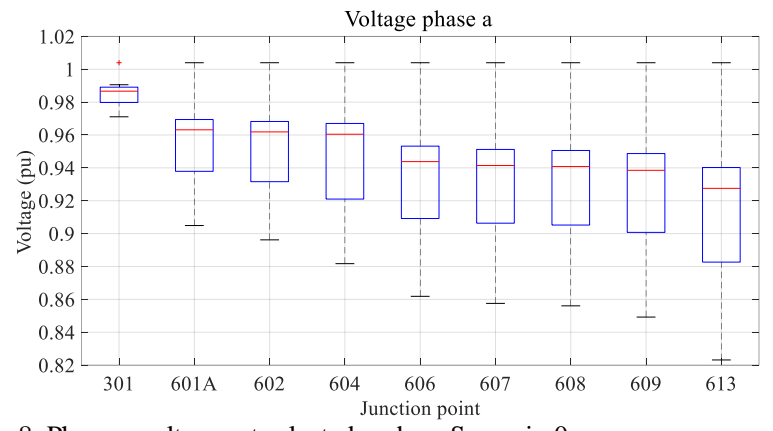

Fig. 8. Phase $a$ voltages at selected nodes - Scenario 0 .

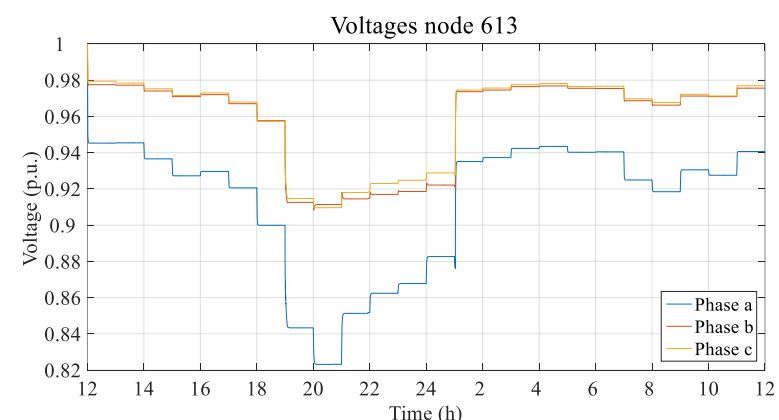

Fig. 9. Phase voltages at node 613 - Scenario 0.

It can be noticed that phase $a$ voltage at node 613 for Scenarios C1 to C4 has its lowest voltages between 19:00 h and 22:00 h. Those three hours are the critical period for the grid, since during that period voltages on phase $a$ are low even when EVs are not plugged-in (Fig. 7). An interesting fact is that it can be observed in Scenarios $\mathrm{C} 1$ to $\mathrm{C} 4$ that voltages on unloaded phases (phases $b$ and $c$ ) rise when the load is increased on the loaded phase (phase $a$ ). The reason behind this phenomenon is that the neutral line is not grounded, i.e. there is a floating neutral line that induces greater voltage unbalance [14]. It also happens the other way, i.e. phase $a$ voltage at node 613 in Scenarios $C 1$ to $C 4$ during the critical period is at some points greater than phase $a$ voltage represented in Fig. 7. This is due to the more balanced situation that the grid experiments during that period.

Controller $\mathrm{C} 1$ behaviour at node 613 is represented in Fig. 10 and Fig. 11, illustrating that between 19:00 h and 21:00 h voltage on phase $a$ at node 613 is below 0.9 p.u.. Controller $\mathrm{C} 1$ is unable to satisfy the voltage standards and, moreover, it introduces voltage oscillations on the grid (Fig. 10).

When the node's voltage is close to 0.9 p.u., EVs are constantly switching between charging with $6 \mathrm{~A}$ and notcharging. In a grid with a high EV penetration, this behaviour can lead to voltage oscillations since several EVs are switching between $6 \mathrm{~A}$ and $0 \mathrm{~A}$ with the same frequency.

In order to satisfy the standards and reduce the voltage oscillations three different Controllers are implemented (C2, $\mathrm{C} 3$ and C4). Controllers' behaviour at node 613 out of the critical period is fairly similar, as it can be seen in Fig. 11, Fig. 12, Fig. 13 and Fig. 14. 


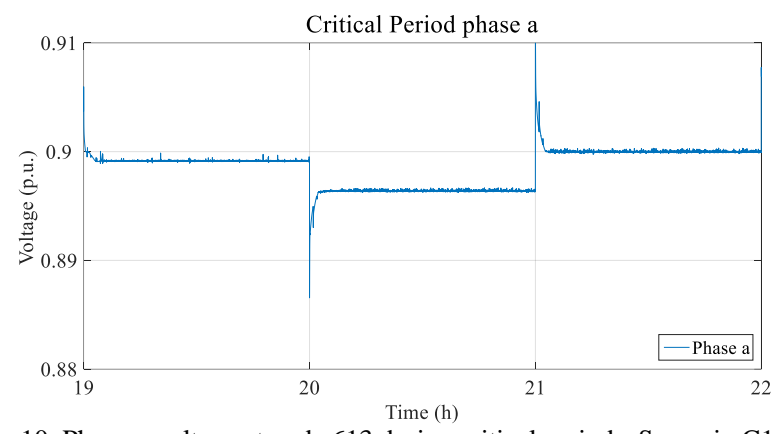

Fig. 10. Phase $a$ voltage at node 613 during critical period - Scenario C1

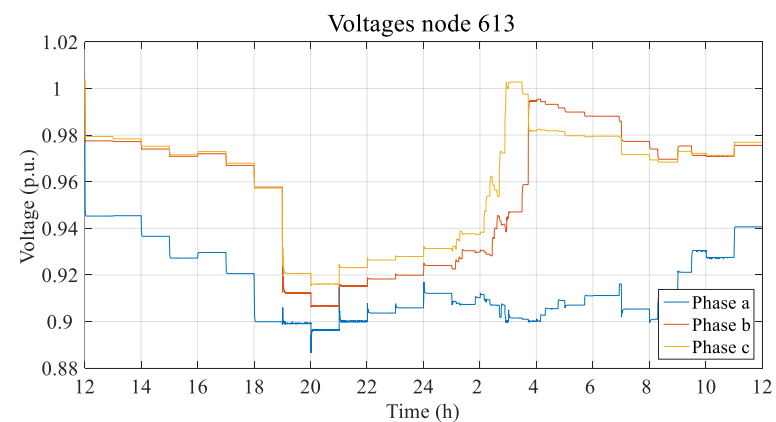

Fig. 11. Phase voltages at node 613 - Scenario C1.

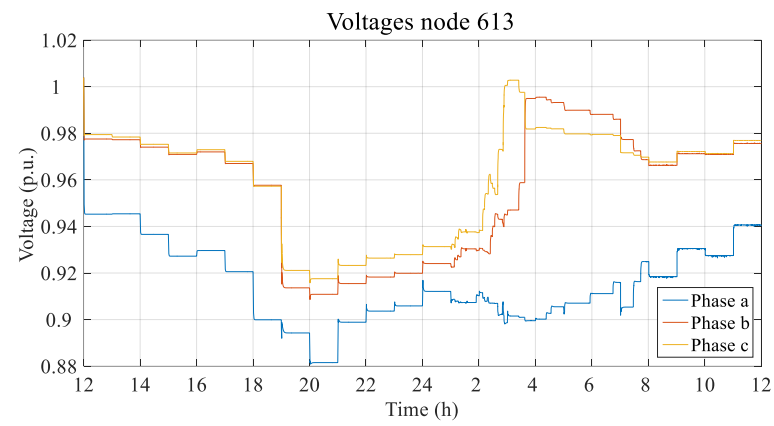

Fig. 12. Phase voltages at node 613 - Scenario C2.

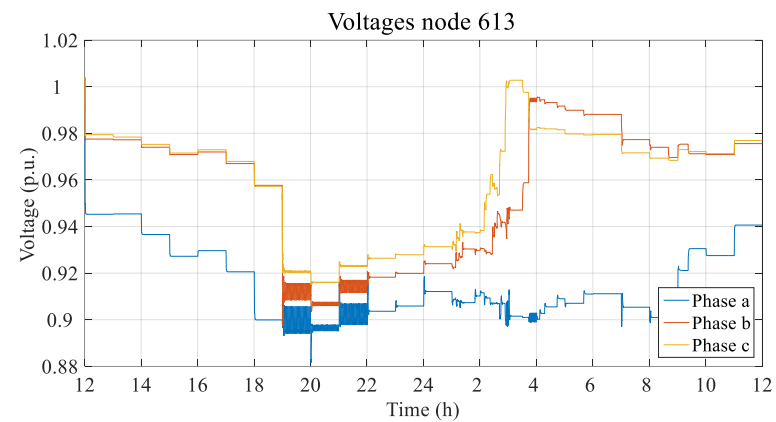

Fig. 13. Phase voltages at node 613 - Scenario C3.

Controllers' behaviour during the critical period is represented in Fig. 15.

Controller C2 eliminates voltage oscillations but, as expected, voltages are the lowest in this scenario because the minimum charging current is limited to $6 \mathrm{~A}$ instead to $0 \mathrm{~A}$ (Fig. 4). EVs located in nodes with low voltages finish to charge their batteries earlier in Scenario C2 than in the rest of Scenarios, but this penalizes the voltages on the phases where
EVs are plugged-in which precludes the grid from satisfying the voltage standards.

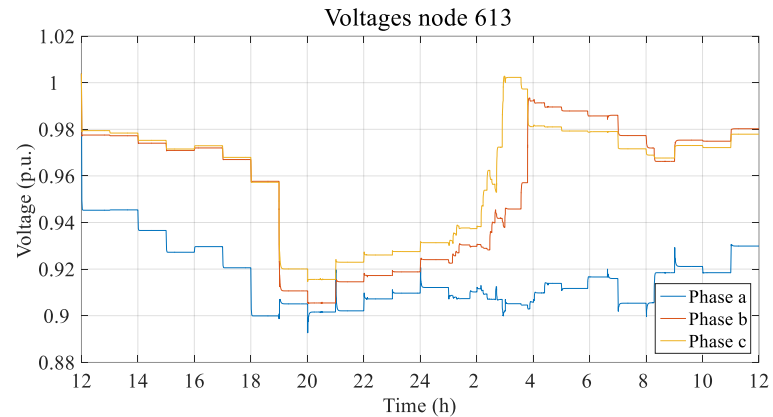

Fig. 14. Phase voltages at node 613 - Scenario C4

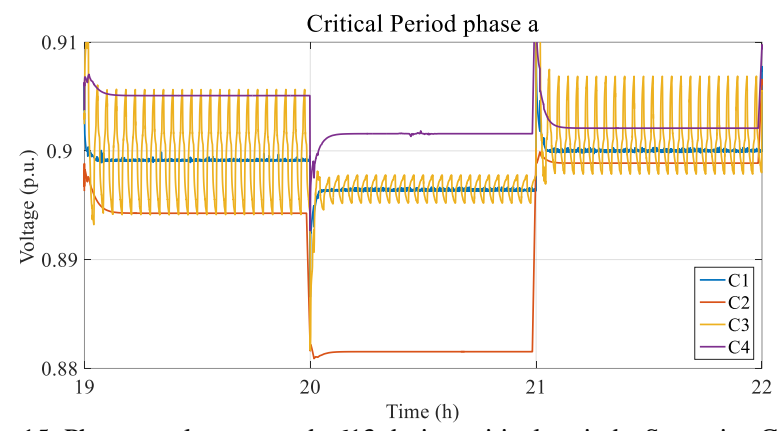

Fig. 15. Phase a voltage at node 613 during critical period - Scenarios C1, C2, $\mathrm{C} 3$ and $\mathrm{C} 4$.

Controller $\mathrm{C} 3$ has the worst behaviour out of the four Controllers. Oscillations in Scenario C3 are wider than Scenario C1 (Fig. 15), and it doesn't improve the voltage levels. Besides, Fig. 16 and Fig. 17 show that voltage average values at the most important nodes are considerably lower in Scenario C3 than Scenario C2, which indicates that this controller is affecting negatively not only to nodes with low voltages, but to the whole network.

Controller $\mathrm{C} 4$ solves both the voltage oscillations and the under-voltages problems, as it can be seen in Fig. 14 and Fig. 15. Fig. 18 shows that node 613 is the only node that presents values below 0.9 p.u.. Those values correspond to voltages reached at 20:00 h (Fig. 15) but, since the 10 minutes average rms voltage value is above 0.9 p.u., the network satisfies the standards.

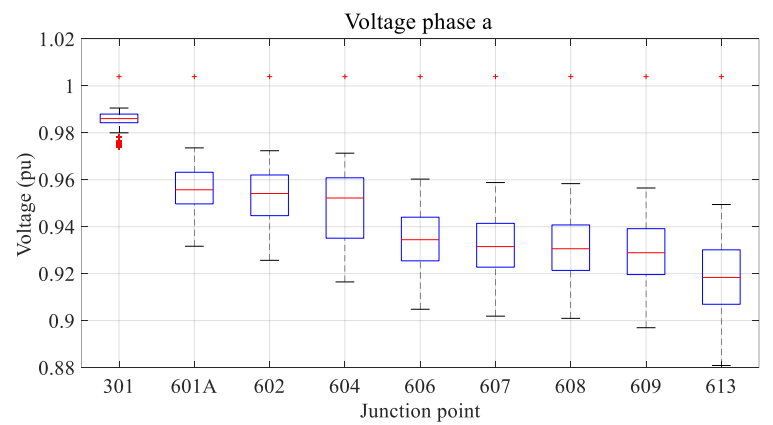

Fig. 16. Phase $a$ voltages at selected nodes - Scenario C2. 


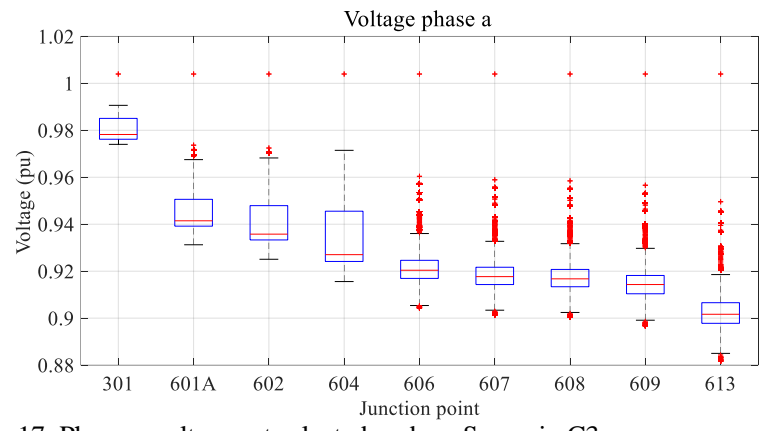

Fig. 17. Phase $a$ voltages at selected nodes - Scenario C3.

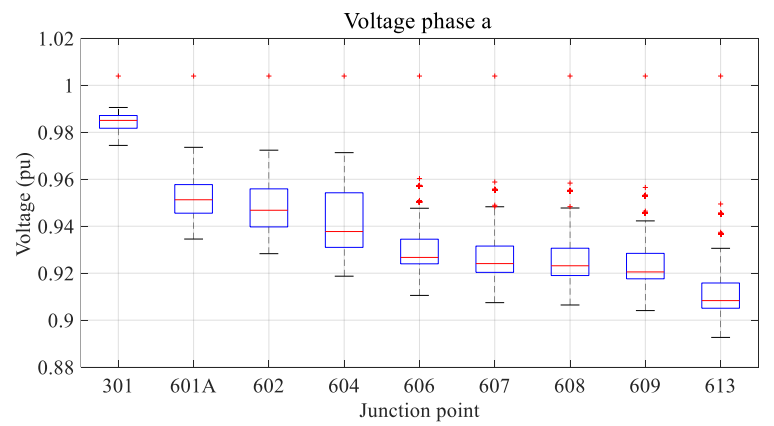

Fig. 18. Phase $a$ voltages at selected nodes - Scenario C4.

\section{CONCLUSION}

This work presents four decentralized controller variations to control the EV charging current taking into consideration that voltages at every node have to satisfy the voltage standards. Uncontrolled EV charging can yield under-voltages, which reduces the reliability and the power quality of the network, especially in unbalanced networks. It has been shown that a simple Droop Control as Controller C1 can considerably improve the network behaviour, even though it produces voltage oscillations and some nodes have under-voltages. Controller C3 has not been successful in solving both problems, but Controller $\mathrm{C} 2$ has proved to solve the voltage oscillations problem, although it was unable to increase the voltages of the furthest node from the transformer above the minimum allowed level. Controller $\mathrm{C} 4$ solved both problems, having proved that a simple Droop Control together with a hysteresis comparator can significantly improve the power quality. This controller unsynchronises the EVs behaviour, and also balances the phases during critical hours resulting in higher voltage levels even compared the case when no EVs are connected. This controller is relatively cheap and could be easily implemented in the EVSE since it is only dependent on local phase-to-neutral voltage measurements.

\section{ACKNOWLEDGMENT}

This work is supported by the Danish Research Project "NIKOLA - Intelligent Electric Vehicle Integration" under ForskEL contract nr. 2013-1-12088. More information at www.nikolaproject.info.

\section{REFERENCES}

[1] Ieahev.org (2015). Denmark - Policies and Legislation - Denmark|IA$H E V$. [Online]. Available: http://www.ieahev.org/by-country/denmarkpolicy-and-legislation/.

[2] G. A. Putrus, P. Suwanapingkarl, D. Johnston, E. C. Bentley, and M Narayana, "Impact of electric vehicles on power distribution networks", in Proc. IEEE Veh. Power Propulsion Conf., Sep. 2009.

[3] Voltage Characteristics in Public Distribution Systems, UNE - EN 50160, 2011.

[4] A. Al-Awami, E. Sortomme, G. Akhtar, and S. Faddel, "A VoltageBased Controller for an Electric Vehicle Charger", IEEE Transactions on Vehicular Technology, 2015.

[5] A. A. Eajal, M. F. Shaaban, E. F. El-Saadany, and K. Ponnambalam, "Fuzzy logic-based charging strategy for Electric Vehicles plugged into a smart grid", in Smart Energy Grid Engineering (SEGE), 2015 IEEE International Conference on , pp. 1-6, 2015.

[6] K. Knezović, M. Marinelli, R. Juul Møller, P. Bach Andersen, C. Træholt and F. Sossan, "Analysis of Voltage Support by Electric Vehicles and Photovoltaic in a Real Danish Low Voltage Network," Universities Power Engineering Conference (UPEC), Sep. 2014

[7] M.Marinelli, "Wind Turbine and Electrochemical Based Storage Modeling and Integrated Control Strategies to Improve Renewable Energy Integration in the Grid", Ph.D. dissertation, University of Genova, 2011.

[8] F. Baccino, M. Marinelli, P. Nørgård, and F. Silvestro, "Experimental testing procedures and dynamic model validation for vanadium redox flow battery storage system," Journal of Power Sources, vol. 254, pp. 277-286, 15 May 2014.

[9] Idaho National Laboratory, "BEV Battery Testing Results 2012 Mitsubishi iMiev - VIN 4550", Idaho National Laboratory, 2012.

[10] A. Kieldsen, A. Thingvad, S. Martinenas and T. Meier Sørensen, Efficiency Test Method for Electric Vehicle Chargers, EVS29 Symposium, Montreal, Quebec, Canada, June 19-22, 2016.

[11] "EV Charge Control - Phoenix Contact", Phoenix Contact, 2016. [Online].

Available: https://www.phoenixcontact.com/assets/downloads_ed/global/web_dwl_ promotion/52001478_EN_HQ_low_EV5Charge_Control.pdf

[12] M. Marinelli, S. Martinenas, K. Knezović, and P. B. Andersen, "Validating a centralized approach to primary frequency control with series-produced electric vehicles," J. of Energy Storage, vol. 7, pp.6373, Aug. 2016

[13] L. Bickers, "Schmitt trigger circuit with picosecond risetimes", Electron. Lett., vol. 17, no. 19, p. 695, 1981.

[14] S. Martinenas, K. Knezović, and M. Marinelli, "Management of Power Quality Issues in Low Voltage Networks using Electric Vehicles: Experimental Validation," Power delivery, IEEE Transactions on under review. 